\title{
An Analysis of Different Grade Levels of Elementary School Students' Reasoning about the Changes of State of Water within a Learning Progression
}

\author{
JueunJung \\ Jagok Elementary School, \\ Seoul, o6373, Republic of Korea \\ 931333@naver.com \\ Jina Chang \\ Seongil Elementary School, \\ Seoul, 05396, Republic of Korea \\ jinachang83@gmail.com \\ Jisun Park \\ Corresponding author, \\ Department of Elementary Education, College of Education, Ewha Womans \\ University, \\ Seoul, o376o, Republic of Korea \\ jpark29@ewha.ac.kr
}

Received: 13 July 2020 | Revised: 29 September 2020 |

Accepted: 5 November 2020

\begin{abstract}
The purpose of this study is to examine how the reasoning of elementary school students develops and progresses within a learning progression. In order to do this, we analyzed third, fourth, and fifth grade elementary school students' levels of reasoning about phenomena related to changes of state of water. The results show that higher grades include higher proportions of students who showed higher-level reasoning. Every student explained the phenomenon at the macroscopic scale; however, fifth grade students considered more elaborate factors and the relationships between those


factors than third and fourth grade students did. In addition, students reasoned contradictorily that the weight would increase in situations of both melting and freezing. Finally, we discuss how science curriculums in each grade can be structured as a progression in reasoning and how to provide appropriate science instruction in terms of students' long-term progression of reasoning.

\section{Keywords}

conceptual understanding - reasoning - learning progression - state of water

\section{Introduction}

Students develop and elaborate on understanding core concepts in science and doing scientific inquiry practices through appropriate science instruction over years (Corcoran et al., 2009). Learning-progression research has investigated pathways of students' science learning along the K-12 education track (Corcoran et al., 2009). Pathways in science learning have usually described students' progress in their knowledge and practice. For example, in terms of scientific knowledge, Jin and Anderson (2012) established a learning progression in students' understanding of energy, one of the essential big ideas in science. In terms of scientific practice, Schwarz et al. (2012) developed a learning progression for students' modelling.

Within a long-term learning progression, students develop and extend their knowledge and practices through accumulating various learning experiences in everyday science classes. For example, students' content understanding and practices in a specific area can transfer and extend across various areas (Bamberger \& Davis, 2013; Schwarz et al., 2012). That is, students' everyday scientific practices such as reasoning and modelling in science classes can be adapted and extended across various science topics in a way that gradually constructs their long-term learning progression.

With this in mind, our hypothesis is that a long-term progression in science learning can be constructed by experiencing small-scale learning activities in regular science instruction. Especially for young students, a small-scale learning experience in an everyday class can have a more significant impact on a learning progression because young students have relatively fewer learning experiences. Considering this aspect, it is important that elementary school students' learning progression needs to be explored in connection with students' understanding of the small-scale concepts and practices they experience in science classes. 
Hence, in this study, we focused on small-scale science concepts and practices that could advance students' learning progression. Specifically, we examined a small-scale pathway of elementary school students' reasoning about changes of state of water. Based on the content in the Korean elementary science curriculum, we investigated students' reasoning about changes of state of water as an important foundation for establishing a learning progression on the water cycle and energy.

In sum, within a learning progression, we analyzed elementary school students' reasoning in different grades about changes of state of water. In addition, we analyzed how the different grade levels of the science curriculum are involved in students' reasoning progress. Through this, we sought to draw educational implications as a basis for establishing a learning development process.

\section{Theoretical Background}

\subsection{Elementary School Students' Reasoning}

Students develop their reasoning gradually by participating in cognitive and social learning processes. The reasoning ability of middle school students is more scientific and logical than that of elementary school students. Elaborative reasoning includes concrete evidence to elicit abstract concepts or models by revealing relationships between key factors in phenomena (Braaten \& Windschitl, 2011; Osborne \& Patterson, 2010).

Within a learning progression, students develop their reasoning ability to a higher level. For example, Gunckel et al. (2012) established a learning process of reasoning that includes four levels, as shown in Table 1.

TABLE 1 A learning progression in reasoning about the carbon cycle (Gunckel et al., 2012)

Level Pathway in reasoning about carbon cycle

Structure-first focusing on naming Principle-first focusing on explaining

$4 \quad$ Processes and systems constrained by principles

3 Chemical change with unsuccessful Principled accounts at molecular

constraints scale without chemical details

$2 \quad$ Hidden mechanisms involved in Successful conservation at events macroscopic scale

$1 \quad$ Force-dynamic accounts of actors and events 
As shown in Table 1, Gunckel et al. (2012) reported that the students at Level 1 interpreted the presented phenomena by considering objects as actors. At Level 2, students built their own explanations in observable categories or interpreted hidden mechanisms for phenomena. The students at Level 3 could describe phenomena from a molecular perspective and deal with chemical changes. Finally, at Level 4, students interpreted the presented phenomena using science principles.

Gunckel et al. (2012) reported that elementary school students' reasoning progressed along two different Level 2 pathways, which indicates that elementary school students' progress in learning does not follow a simple pathway. In the context of actual learning, students develop their knowledge and practices along much more multidimensional pathways. Considering this, it is necessary to take into account more elaborate features that are shown in each level. Thus, we tried to explore more elaborate learning pathways of elementary students' reasoning.

\subsection{Students' Understanding of the Changes of State of Water}

Change in state is a basic and key concept in understanding the big ideas of the water cycle and energy cycles. Students' understanding of the concept of changes of state has been investigated in science education for decades (Osborne \& Cosgrove, 1983; Anderson, 1990). However, it has also been reported that the concept of "state" is difficult for young children to understand clearly (Anderson, 199o; Black et al., 2011). To help young students understand this concept easily, many educators have considered water a context in helping elementary school students understand changes of state (Paik et al., 2004), because state changes of water are very familiar for young students.

So far, transitions between the three states have usually been reported and summarized into two main themes (Balck et al., 2011): the solid-liquid transition (i.e., melting and freezing) and the solid-gas transition (i.e., evaporation and condensation). This study, as many previous studies have done, will also focus on these two main themes in order to investigate students' understanding about melting, freezing, evaporation, and condensation of water.

\subsubsection{Solid-Liquid Transition: Melting and Freezing}

The most confusing feature of melting and freezing is the conservation of weight. Students were reported to confuse the weight of a matter with its other physical traits (Ross \& Law, 2003). For example, students explained that ice would weigh more than the water that froze because the ice is hard, while chocolate would decrease in weight when it melts because the chocolate is softer. Meanwhile, to understand the conservation of weight, it is essential for 
students to interpret phenomena from the particle perspective, because the conservation of particles can be a foundation to understanding the concept (Ross \& Law, 2003). However, Paik et al. (2004) reported that young students did not use a particle model in explaining melting and freezing.

\subsubsection{Solid-Gas Transition: Evaporation and Condensation}

Among the three states of matter, gas has been considered the most difficult substance to understand because of its invisibility (Black et al., 2011). Because of this, students have many challenges with evaporation and condensation. For example, it was reported that students thought that a liquid disappears in evaporation (Tytler \& Peterson, 2005). Furthermore, evaporation and condensation are very familiar experiences; however, sometimes these experiences can appear to be contradictory to the results of practical work, which causes a great deal of conceptual confusion for young students. Considering previous reports, we investigated how these contradictions occur in students' reasoning and how students' reasoning developed or progressed depending on the science curriculum of each grade.

\section{$3 \quad$ Research Methods}

\subsection{Developing Assessment Items}

This study sought to examine elementary school students' reasoning about science concepts as a basis of developing a large-scale learning progression. To accomplish this, we developed writing assessment items for elementary school students to reason about phenomena related to the changes of state of water. The researchers selected phenomena involved in changes of state of water and its related concepts. With the purpose of this study in mind, we considered the following two aspects in terms of understanding concepts and reasoning.

First, it has been reported that elementary school students have more difficulty in explaining the process of state changes related to invisible gas than they do with other state changes (Black et al., 2011). Since elementary school students, for example, tend to have a variety of alternative concepts about the state of water vapor and may not yet be able to interpret clearly the phenomena related to evaporation and boiling, assessment items were developed to explain and reason about these phenomena.

Second, Kim (2018) reported that elementary teachers experienced particular difficulty in teaching changes in weight and volume of water when it freezes and melts, and students also experienced difficulty in learning this scientific concept. Teachers responded that practical work involving measuring 
and the weight and volume of water when it freezes and melts did not go well and could result in students' misconceptions. Students responded that they felt that this concept was difficult as they did not know why the weight did not change while the volume changes when water freezes or melts.

Since it was clear that both teachers and students had difficulty in teaching and learning explanations for the process of state change between gas and liquid and the weight and volume change between ice and water, these two big ideas were chosen as assessment items among the state change processes of water.

This assessment had five items and each item was an open-ended question in an everyday context in order to elicit students' reasoning processes (see Table 2 and Figure 1).

TABLE 2 Content of assessment items

\begin{tabular}{|c|c|c|}
\hline $\begin{array}{l}\text { Item } \\
\text { number }\end{array}$ & Scientific concept & Title of question \\
\hline 1 & & $\begin{array}{l}\text { What will happen to its weight when water } \\
\text { freezes? }\end{array}$ \\
\hline 2 & $\begin{array}{l}\text { Weight and volume } \\
\text { change in melting and }\end{array}$ & $\begin{array}{l}\text { What will happen to the weight of this cup of } \\
\text { water and ice when the ice melts? }\end{array}$ \\
\hline 3 & freezing & $\begin{array}{l}\text { What will happen to the volume of this cup of } \\
\text { water and ice when the ice melts? }\end{array}$ \\
\hline 4 & $\begin{array}{l}\text { Condensation and } \\
\text { evaporation }\end{array}$ & $\begin{array}{l}\text { Where do the water droplets come from on } \\
\text { the outer surface of a cup of ice water? }\end{array}$ \\
\hline 5 & & How do wet clothes dry? \\
\hline
\end{tabular}

3. Jin is trying to drink the ice water in the cup, but suddenly her mom gave her an errand so she couldn't drink and left it in the house. Jin started to worry that the ice would melt and cause the water to overflow out of the cup.

What will happen to the level of water in the cup when the

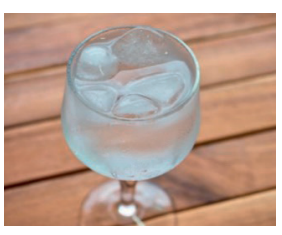
ice melts? Why do you think this?

FIGURE 1 An example of a question about volume change in melting 


\subsection{The Participants and Data Collection}

The student participants were 91 students in Grades 3, 4, and 5 at the elementary level. As the purpose of this study was to explore how elementary school students develop scientific reasoning depending on whether they had learned the scientific content involving changes of state of water, we chose some participants who had not learned the concepts related to the changes of state of water ( 53 students in Grades 3 and 4 ) and some who had ( 38 students in Grade 5). The participant students responded to open-ended questions developed to analyze students' reasoning about the changes of state of water.

\subsection{Data Analysis}

To construct an analysis framework for students' responses to the assessment items, we considered both theoretical rationale and empirical evidence. In other words, we established the levels of students' development based on both the theoretical rationale of the previous studies and the empirical data of this study. That is, in terms of establishing an analytic framework, we tried to reflect simultaneously both the results of previous studies and the empirical data found in this study.

The analytic framework was developed for assessing elementary school students' scientific reasoning. To accomplish this, within a learning progression of reasoning (Gunckel et al., 2012), we focused on Level 2 by considering the content areas of elementary science and curriculums in Korea. In other words, we elaborated the sub-levels of Level 2 depending on how the students interpreted the phenomenon on a macroscopic scale and constructed a sophisticated explanation. By using an analytic framework constructed in this way, we were able to establish four levels in elementary school students' reasoning about changes in the state of water, as shown in Table 4.

TABLE 3 Student participants' information

\begin{tabular}{|c|c|c|}
\hline \multicolumn{2}{|c|}{$\begin{array}{l}\text { Number of the } \\
\text { participants }\end{array}$} & Content of the curriculum learned at each grade level \\
\hline Grade 3 & 25 & $\begin{array}{l}\text { The students had learned the states of matter but had not yet } \\
\text { learned the changes of state of water and the water cycle. }\end{array}$ \\
\hline Grade 4 & 28 & $\begin{array}{l}\text { The students had learned the states of matter but had not yet } \\
\text { learned the changes of state of water and the water cycle. }\end{array}$ \\
\hline Grade 5 & 38 & $\begin{array}{l}\text { The students had learned the states of matter, the changes of } \\
\text { state of water, and the water cycle. }\end{array}$ \\
\hline
\end{tabular}




\section{Level Description (and example)}

In explaining why a phenomenon happened, students consider the related key factors and their relationships at a macroscopic (i.e., observable) scale. ("This is because of condensation. The vapor became water droplets as the relatively warm air met the cold water.")

2 To explain why a phenomenon happened, students consider only some parts of the related key factors at a macroscopic scale.

("It seems that water droplets are formed as the warm air meets the cold air.") relevant factors or explain only their experiences.

("It seems to have come from humidity. Because it becomes humid as it is a hot summer day.")

o Students describe only what happened in a phenomenon and do not explain why it happened.

("It is moisture. Because I have experienced this and I think I asked my mom.")

\section{$4 \quad$ Results}

We reported the progressions of students' reasoning by investigating the levels of students' responses to two topics related to changes of state of water: (1) weight and volume change in melting and freezing and (2) the cause of condensation and evaporation.

\subsection{Topic 1: Weight and Volume Change in Melting and Freezing}

\subsubsection{What Will Happen to Its Weight When Water Freezes?}

We explored the level of students' reasoning about whether weight changes when water freezes. Overall, the higher the grade, the higher the proportion of students who showed higher levels of reasoning.

Level 3 reasoning, which is the highest reasoning level in this study, involves explaining that there is no change in weight in connection with no change in the total amount of the material even though there is a volume change when water freezes. Grade 3 students who did not learn the scientific concept that there is no weight change but volume change when water melts and freezes did not show Level 3 reasoning. Of the Grade 4 students who also had not yet learned this scientific concept but were scheduled to learn it a month later, 
$21.4 \%$ showed Level 3 reasoning. Of Grade 5 students, who had learned this scientific concept a year before, $26.3 \%$ showed Level 3 reasoning. In Level 3 reasoning responses, two students in Grade 5 showed reasoning about possible outcomes in everyday life rather than the ideal situation in the question. These students answered that the weight of a bottle would increase because the difference in temperature inside and outside of bottle causes water droplets on the bottle that have condensed from water vapor. Although the question was intended to ask students whether they know that there is no weight change, these students answered that there would be weight change because of the water droplets on the bottle. These students incorporated two different scientific concepts: mass conservation and condensation.

Level 2 reasoning involved students explaining weight changes in relation to physical changes such as volume change or temperature change. Twenty percent of Grade 3, 53.6\% of Grade 4, and $57.9 \%$ of Grade 5 students showed Level 2 reasoning. Although more than $50 \%$ of both Grades 4 and 5 students showed Level 2 reasoning, we could see differences in the responses between Grades 3 and 4 and Grade 5. More students in Grade 4 answered that the weight would increase because the volume increased. However, more students in Grade 5 answered that the weight would be same although the volume increased. That is, Grades 3 and 4 students who had not learned the scientific concept yet showed reasoning in relation to weight and volume that led to scientifically incorrect conclusions. Grade 5 students who had learned the scientific concept when they were Grade 4, however, gave scientifically correct answers but with phenomenological reasoning, simply saying that volume and weight are irrelevant.

Level 1 reasoning responses relied on the students' own experience, such as heaviness of the frozen bottle when lifted, or relied on the sense of touch, such as reporting hardness. Forty-eight percent of Grade 3, 17.9\% of Grade 4, and $10.5 \%$ of Grade 5 students showed Level 1 reasoning.

TABLE 5 Students' responses on the item about the weight of a water bottle

\begin{tabular}{lccc}
\hline Level & Grade 3 & Grade 4 & Grade 5 \\
\hline 3 & o (o\%) & $6(21.4 \%)$ & $10(26.3 \%)$ \\
2 & $6(20 \%)$ & $15(53.6 \%)$ & $22(57.9 \%)$ \\
1 & $12(48 \%)$ & $5(17.9 \%)$ & $4(10.5 \%)$ \\
0 & $7(28 \%)$ & $0(0 \%)$ & $2(5.3 \%)$ \\
Total & $25(100 \%)$ & $28(100 \%)$ & $38(100 \%)$ \\
\hline
\end{tabular}


What Will Happen to the Weight and Volume of This Cup of Water and Ice When the Ice Melts?

We explored the level of students' reasoning about changes in weight and volume when ice melts by asking what this cup of water and ice will weigh and what its volume will be when the ice melts.

In this question about weight and volume, $31.6 \%$ of Grade 5 and $14.3 \%$ of Grade 4 students showed Level 3 reasoning, explaining that there would be no weight change as there was no change in the total amount of water and ice but only a state change.

Forty-four point seven percent of Grade 5, 60.7\% of Grade 4, and 44\% of Grade 3 students showed Level 2 reasoning. In Level 2 reasoning, students' responses were grouped into three categories: (1) The weight will increase as water will be added when ice melts, (2) the weight will decrease as ice is heavier than water, and (3) the weight will be same although the volume changes. Not all the students who answered that the weight will increase when water freezes responded that the weight will decrease when the ice melts. Only nine students showed consistent responses although they were reasoning at Level 2. Interestingly, many students who answered that the weight will increase when the water freezes also responded that the weight would increase when the ice melts. Their reasoning became contradictory because of the intuitive reasoning that melting ice will add water.

Thirty-six percent of Grade 3, $25 \%$ of Grade 4 , and $18.4 \%$ of Grade 5 students showed Level 1 reasoning. Most students responded that the weight will increase because of the addition of more water. The relationship between state change and weight was not mentioned by any of the students.

For the question about the volume change of a cup of ice and water when the ice melts, scientifically correct responses were that there was no volume change of this cup of ice and water when the ice melts. Although the volume

TABLE 6 Students' responses on the item about weight of a cup of water and ice

\begin{tabular}{lccc}
\hline Level & Grade 3 & Grade 4 & Grade 5 \\
\hline 3 & $\circ(0 \%)$ & $4(14.3 \%)$ & $12(31.6 \%)$ \\
2 & $11(44 \%)$ & $17(6 \circ .7 \%)$ & $17(44 \cdot 7 \%)$ \\
1 & $9(36 \%)$ & $7(25 \%)$ & $7(18.4 \%)$ \\
0 & $5(20 \%)$ & $\circ(0 \%)$ & $2(5 \cdot 3 \%)$ \\
Total & $25(100 \%)$ & $28(100 \%)$ & $38(100 \%)$ \\
\hline
\end{tabular}


will decrease when the ice melts into the water, the level of water in this cup will not change much considering the fact that the ice cube is floating in the cup of water and ice. Considering the floating ice cube, however, may go beyond the curriculum. Therefore, a student's response that the level of water in the cup will decrease when the ice melts because the volume decreases when ice melts was coded as Level 3 reasoning. Fifteen point eight percent of Grade 5 and $7.1 \%$ of Grade 4 students showed Level 3 reasoning. As we expected, there was no student who considered the floating part of the ice in this study.

Twenty-eight point nine percent of Grade 5, 39.3\% of Grade 4, and $20 \%$ of Grade 3 students showed Level 2 reasoning. Like the Level 2 reasoning about weight shown by students above, students explained that the water level will go up because water will be added when the ice melts. This reasoning showed that it is difficult for students to consider the submerged portion of the ice and to associate it with volume. Students showed reasoning associated with amount of water, which is not volume.

Level 1 reasoning tended to simply restate the question, which asked what the level of the water in the cup would be when the ice melts. Most of the Level 1 reasoning statements were that the water in the cup would increase when the ice melts, which is simply a restatement of the question. Fifty-six percent of Grade 3, 53.6\% of Grade 4, and 50.0\% of Grade 5 students showed Level 1 reasoning about this question.

\subsection{Topic 2: Condensation and Evaporation}

4.2.1 Where Do the Water Droplets on the Outer Surface of a Cup of Ice Water Come From?

On the topic of the change of state of gases, we asked students to explain the phenomenon of water droplets forming on the outer surface of a cup of water and ice. Thirty-four point two percent of Grade 5 and $14.3 \%$ of Grade 4

TABLE 7 Students' responses on the item about the volume of a cup of water and ice

\begin{tabular}{lccc}
\hline Level & Grade 3 & Grade 4 & Grade 5 \\
\hline 3 & $0(0 \%)$ & $2(7.1 \%)$ & $6(15.8 \%)$ \\
2 & $5(20 \%)$ & $11(39.3 \%)$ & $11(28.9 \%)$ \\
1 & $14(56 \%)$ & $15(53.6 \%)$ & $19(50.0 \%)$ \\
0 & $6(24 \%)$ & $0(0 \%)$ & $2(5.3 \%)$ \\
Total & $25(100 \%)$ & $28(100 \%)$ & $38(100 \%)$ \\
\hline
\end{tabular}


TABLE 8 Students' responses on the item about water droplets on the outer surface of a cup

\begin{tabular}{lccr}
\hline Level & Grade 3 & Grade 4 & \multicolumn{1}{c}{ Grade 5} \\
\hline 3 & o (०\%) & $4(14.3 \%)$ & $13(34.2 \%)$ \\
2 & $5(20 \%)$ & $17(60.7 \%)$ & $14(36.8 \%)$ \\
1 & $12(48 \%)$ & $5(17.9 \%)$ & $6(15.8 \%)$ \\
0 & $8(32 \%)$ & $2(7.1 \%)$ & $5(13.2 \%)$ \\
Total & $25(100 \%)$ & $28(100 \%)$ & $38(100 \%)$ \\
\hline
\end{tabular}

students showed Level 3 reasoning. These students explained that vapor in the air condensed or changed into water droplets as vapor met the surface of the cold cup.

Two kinds of Level 2 reasoning responses were found: (1) The state change into water occurs because of the temperature difference inside and outside the cup with no mention of water from vapor in the air, and (2) the water on the outside of the cup came from vapor in the air with no mention of the temperature difference that caused the vapor to change into water.

In Level 1 reasoning, irrelevant factors were associated the condensation, such as hot weather and rain. Some students also simply mentioned humidity or the air in their responses. Some students thought water was leaking from the cup.

\subsubsection{How Do Wet Clothes Dry?}

On the topic of the change of state from liquid to gas, we asked students to explain how wet clothes dry in order to determine whether students can reason about evaporation. Fifty percent of Grade $5,35.7 \%$ of Grade 4 , and $12 \%$ of Grade 3 students showed Level 3 reasoning about this question. Level 3 reasoning involves explaining that water is turned into vapor because of heat or sunlight.

Students' responses explaining only the state change from water to vapor were categorized as Level 2 reasoning. Also, responses mentioning a cause of drying such as heat or warm temperature but using the word "dry" without mentioning state change were categorized as Level 2 reasoning. Eight percent of Grade 3, $17.9 \%$ of Grade 4, and 44.7\% of Grade 5 students showed Level 2 reasoning.

In Level 1 reasoning, students mentioned simple factors that they often experience in everyday life, such as air conditioners, wind, and sunlight, 
TABLE 9 Students' responses on the item about drying wet clothes

\begin{tabular}{lccc}
\hline Level & Grade 3 & Grade 4 & Grade 5 \\
\hline 3 & $3(12 \%)$ & $10(35 \cdot 7 \%)$ & $19(5 \circ \%)$ \\
2 & $2(8 \%)$ & $5(17.9 \%)$ & $17(44.7 \%)$ \\
1 & $20(80 \%)$ & $13(46.4 \%)$ & $2(5 \cdot 3 \%)$ \\
0 & $0(0 \%)$ & $0(0 \%)$ & $0(0 \%)$ \\
Total & $25(100 \%)$ & $28(100 \%)$ & $38(100 \%)$ \\
\hline
\end{tabular}

without mentioning how these factors make clothes dry. Eighty percent of Grade 3, 46.4\% of Grade 4, 5.3\% of Grade 5 students showed Level 1 reasoning.

This study investigated how elementary school students' reasoning developed and progressed within a learning progression by analyzing the reasoning levels of Grades 3, 4, and 5 students about phenomena related to changes of state of water. Students were asked to explain two types of phenomena related to changes of state of water: (1) weight and volume change in melting and freezing and (2) the causes of condensation and evaporation.

As a result of the analysis, higher grade-level students show higher proportions of responses at higher levels on all items. Every participant student was able to explain the presented phenomena at the macroscopic scale. Even though every student explained phenomena at an observable scale, the fifth grade students were able to consider more complicated and elaborative factors in the same phenomenon than the third grade students could. The third grade students tended to rely on their own experience to explain the phenomena instead of investigating the detailed factors.

Meanwhile, in students' responses, many examples of contradictory reasoning were found in interpreting the relationships among the related factors (e.g., weight, volume, amount of matter, and floating on the water). For example, students contradictorily explained that the weight would increase in every situation of both melting and freezing. Some students intuitively reasoned that the weight of ice would increase because the volume of ice is bigger than water. At the same time, other students explained based on their empirical reasoning that ice is lighter than water because the ice floats on the water. However, in an actual experiment, the students will observe 
the unexpected result that the weight does not change in every situation of melting and freezing.

This unexpected experimental result could cause a conceptual contradiction for elementary school students, which causes the need for students to establish another alternative reasoning to explain this contradiction properly. If students do not have any pedagogical chances to explain this contradiction properly, students' reasoning about this phenomenon will not develop into scientific ways within a learning progression. In this context, the "appropriate science instruction" mentioned by Corcoran et al. (2009) plays a critical role for students in going through a learning progression.

This issue needs to be widely discussed in association with the content covered in science curriculums. Changes of state of water is addressed in the 2015 revised curriculum for Grades 3 and 4. This current elementary science curriculum in Korea covers activities that only involve observing the changes in volume and weight as water freezes and melts and condensation and evaporation phenomena, while analyzing and interpreting the factors related to these phenomena is not covered. In other words, Korean elementary school students only learn scientific knowledge explicitly and do not have a chance to think about the relationships between related factors using scientific reasoning. Considering that change of state of water is closely associated with other scientific concepts such as weather, which is addressed in the elementary science curriculum for Grades 5 and 6, providing learning opportunities for students to think about the relationships between related factors in change of state of water can help their future learning at the elementary level.

Within a long-term learning progression, chances given to explain hidden mechanisms involved in events can be a stepping stone to the next level of a learning progression. For instance, elementary students who have had a chance to reason about phenomena related to temperature, which is a hidden mechanism, can develop their reasoning in a more sophisticated manner if they learn the chemical structure of water and ice from a molecular perspective when they become secondary students. Therefore, this study can give practical implications for teaching the changes of states of water in terms of how to provide appropriate science instruction for students' going through a long-term progression.

\section{Abbreviation}




\section{Ethical Considerations}

The data collected from this paper has obtained the necessary clearance from guardians and the students involved in the study.

\section{About the Authors}

Jueun Jung is an elementary school teacher in Seoul, South Korea. She received her master's degree at Ewha Womans University from the Department of Elementary Education. She is interested in students' conceptual understanding and effective strategies for teaching it.

Jina Chang is a researcher and a teacher at Seongil Elementary School, Seoul, South Korea. Her research interests are in the areas of school science inquiry, primary science education, and sociocultural contexts. She has expanded her research interests into the impacts of technologies in inquiry from sociocultural perspectives.

Jisun Park is an assistant professor at Ewha Womans University in the Department of Elementary Education. Her research interests include practical work in school science, socio-scientific issues, and teacher professional development.

\section{References}

Andersson, B. (1990). Pupils' conceptions of matter and its transformations (ages 12-16). Studies in Science Education, 18, 53-85.

Bamberger, Y. M., \& Davis, E. A. (2013). Middle-school science students' scientific modelling performances across content areas and within a learning progression. International Journal of Science Education, 35 (2), 213-238.

Black, P., Wilson, M., \& Yao, S. Y. (2011). Road maps for learning: A guide to the navigation of learning progressions. Measurement:Interdisciplinary Research \& Perspective, $9(2-3), 71-123$.

Braaten, M., \& Windschitl, M. (2011). Working toward a stronger conceptualization of scientific explanation for science education. Science education, 95 (4), 639-669.

Corcoran, T. B., Mosher, F. A., \& Rogat, A. D. (2009). Learning progressions in science: An evidence-based approach to reform. Consortium for Policy Research in Education.

Gunckel, K. L., Mohan, L., Covitt, B. A., \& Anderson, C. W. (2012). Addressing challenges in developing learning progressions for environmental science literacy. In 
A. C. Alonzo \& A. W. Gotwals (Eds.), Learning progressions in science: Current challenges and future directions (pp. 101-137). Sense.

Jin, H., \& Anderson, C. W. (2012). A learning progression for energy in socio-ecological systems. Journal of Research in Science Teaching, 49 (9), 1149-1180.

Kim, H. (2018). Difficulties of teaching and learning the 'state change of water' in elementary science: Focusing on the 2009 revised science curriculum (Masters dissertation). Gyeongin National University of Education, Gyeonggi-do, South Korea.

Osborne, J. F., \& Patterson, A. (2011). Scientific argument and explanation: A necessary distinction? Science Education, 95 (4), 627-638.

Osborne, R. J., \& Cosgrove, M. M. (1983). Children's conceptions of the changes of state of water. Journal of Research in Science Teaching, 20 (9), 825-838.

Paik, S. H., Kim, H. N., Cho, B. K., \& Park, J. W. (2004). K-8th grade Korean students' conceptions of 'changes of state' and 'conditions for changes of state'. International Journal of Science Education, 26 (2), 207-224.

Ross, K. and Law, E. (2003) Children's naive ideas about melting and freezing. School Science Review, 85 (311), 99-102.

Schwarz, C. V., Reiser, B. J., Acher, A., Kenyon, L., \& Fortus, D. (2012). MoDeLS: Challenges in defining a learning progression for scientific modeling. In A. C. Alonzo \& A. W. Gotwals (Eds.), Learning progressions in science: Current challenges and future directions (pp. 101-137). Sense.

Tytler, R. \& Peterson, S. (2005) A longitudinal study of children's developing knowledge and reasoning in science. Research in Science Education, 35, 63-98. 